\title{
Rapid determination of coenzyme Q10 in cheese using high-performance liquid chromatography
}

\author{
Pamela Manzi • Alessandra Durazzo
}

Received: 27 December 2014 / Revised: 19 February 2015 / Accepted: 28 February 2015 / Published online: 19 March 2015

C) INRA and Springer-Verlag France 2015

\begin{abstract}
Coenzyme Q10, a component of the mitochondrial energy metabolism, plays a key role in maintaining the cellular redox state. The aim of this work was to develop a chromatographic method for rapid determination of coenzyme Q10 in cheeses. Samples were subjected to alkaline digestion $\left(70^{\circ} \mathrm{C}\right.$ for $\left.40 \mathrm{~min}\right)$ and extracted with hexane/ethyl acetate $(9: 1 v / v)$. Coenzyme Q10 was separated by a Phenomenex Kromasil $5 \mu \mathrm{m} \mathrm{Si}$ $250 \times 4.6 \mathrm{~mm}$ column and UV/Vis detector $(275 \mathrm{~nm})$ and eluted with an isocratic mobile phase (2-propanol $1 \%$ in $\mathrm{n}$-hexane, flow rate $1.5 \mathrm{~mL} \cdot \mathrm{min}^{-1}$ ). The linearity test was described by the equation $y=13786 x-258.91$, with a good correlation $\left(R^{2}=0.9985\right)$. The limit of detection was $0.024 \mu \mathrm{g} \cdot \mathrm{mL}^{-1}$, the limit of quantitation was $0.069 \mu \mathrm{g} . \mathrm{mL}^{-1}$, and retention time was $3.90 \mathrm{~min}$. The developed HPLC method is simple, rapid and cheap, and allows a reliable quantitation of coenzyme Q10 in cheeses.
\end{abstract}

Keywords Coenzyme Q10 · Antioxidants · Normal-phase HPLC method · Cheese

\section{Introduction}

Coenzyme Q10 (2,3-dimethoxy-5-methyl-6-polipropenyl-1,4-benzoquinone), also known as ubiquinone 10, is a lipid compound, in the specific, a benzoquinone with 10 isoprene units in the aliphatic chain. In the human body, coenzyme Q10 (CoQ10) originates from endogenous biosynthesis as well as from dietary intake. It is widely distributed in human tissues, especially, in inner membranes of mitochondria where it affects their fluidity and permeability.

Various and sometimes controversial biological functions of ubiquinone are documented (Nohl et al. 2003; Bentinger et al. 2007). CoQ10 is an indispensable electron carrier and is well known for its role in the mitochondrial electron transport chain and oxidative phosphorylation to produce ATP (Crane 2007). It

P. Manzi $(\bowtie) \cdot$ A. Durazzo

Consiglio per la ricerca in agricoltura e l'analisi dell'economia agraria, Centro di Ricerca per gli Alimenti

e la Nutrizione (CRA-NUT), Via Ardeatina 546, 00178 Rome, Italy

e-mail: pamela.manzi@entecra.it 
plays a key role in maintaining the cellular redox state and acts as an antioxidant, inhibiting free radicals and showing synergism with other antioxidants (Bentinger et al. 2007).

CoQ10 deficiencies can be divided in primary deficiency, caused by mutations in genes involved in its biosynthesis, and secondary deficiency, caused by mutations in genes not directly involved in the CoQ10 biosynthesis (Potgieter et al. 2013; Wang and Hekimi 2013). Several reviews confirmed that CoQ10 deficiency can also be associated to a high risk of development of chronic diseases (Quinzii et al. 2007; Ahmadvand and Ghasemi-Dehnoo 2014), such as heart failure, hypertension (Pepe et al. 2007; Rosenfeldt et al. 2007; Bentinger et al. 2010), neurodegenerative disorders, and diabetes (Ates et al. 2013).

CoQ10 can be supplied by diet, and its content is higher in animal products than in plant products (Mattila and Kumpullainen 2001; Pravst et al. 2010). Meat, fish, and vegetable oils are good sources of CoQ10, while vegetables, fruits, and cereals are a very poor source of CoQ10. Differences in CoQ10 content in food items may be possibly due to different food processing, such as boiling, frying, etc.

Milk and dairy products are not generally considered a good source of this molecule, although they are of animal origin, and a remarkable review (Pravst et al. 2010) actually highlighted that dairy products are much poorer in coenzyme CoQ10 than other foods e.g., meat, fish, nuts, or vegetable oils. Many innovative applications in food fortification with CoQ10 were nevertheless studied (Stratulat et al. 2013), and milk and dairy products proved to be very suitable for this purpose (Stratulat et al. 2014). CoQ10 can be incorporated into a cheese and preserve its bioactivity.

So far, several analytical methods have been developed to determine CoQ10 and are based on spectrophotometric, coulometric (Tang et al. 2002), electrochemical (Galinier et al. 2004; Niklowitz et al. 2005), and/or mass spectrometric detectors (RodríguezAcuna et al. 2008). They showed to be nevertheless expensive and affected by food matrix.

The aim of this work was therefore the development of a simple chromatographic method, using a conventional HPLC system with normal-phase column, to obtain a sensitive and accurate, as well as simple and rapid determination of CoQ10 in dairy products. The choice of normal-phase HPLC is due to the fact that silica, a non-bonded phase, provides very high selectivity for many applications, such as determination of geometric and positional isomers or hydrophobic compounds. Moreover, the use of non-polar solvents in the mobile phase guarantees the HPLC system does not operate at very high pressure.

\section{Materials and methods}

\subsection{Samples}

Italian cheeses such as Provola, Bagoss, and Pecorino from an organic farm (1 month ripening) and Pecorino from a conventional farm (2 month ripening) were collected from different Italian farms. All dairy products were sampled, grated, and analyzed in triplicate. 


\subsection{Chemicals and standards}

All solvents were of HPLC or Optima grade, and coenzyme Q10 standard was purchased from Sigma-Aldrich (St Louis, MO, USA). Ultrapure water was prepared by ion exchange system to $>18 \mathrm{~m} \Omega$ resistivity (Millipore, MA, USA).

\subsection{Equipments}

The following equipments were used: a spectrophotometer (Shimadzu, Model 1800, Tokyo, Japan) and an HPLC analytical system, Alliance (Waters model 2695, Milford, MA, USA), with a UV/Vis detector (Waters model 2487, Milford, MA, USA). Results were processed by means of Waters Empower Chromatography System.

\subsection{Preparation of standard solutions}

Stock solution of coenzyme Q10 was prepared in 2-propanol, stored at $-20{ }^{\circ} \mathrm{C}$, and protected from light. The standard concentration was confirmed spectrophotometrically by measuring absorbance at $290 \mathrm{~nm}$ wavelength, and the molar extinction coefficient of coenzyme Q10 (molecular weight 863.37 g.mol ${ }^{-1}$; maximum wavelength $290 \mathrm{~nm}$; molar $\varepsilon$ in 2-propanol 3510) was taken according to Adrian et al. (2010). Stock solution showed good stability when stored at $-40{ }^{\circ} \mathrm{C}$ (1 month). Daily working solutions were prepared to obtain the calibration curve by diluting stock solutions in 2-propanol 1\% in n-hexane: the ranges of working solutions were from 0.810 to $2.025 \mu \mathrm{g} \cdot \mathrm{mL}^{-1}$.

\subsection{Sample treatments and chromatographic conditions}

Coenzyme Q10 in cheese samples was extracted according to Panfili et al. (1994), that is, $0.5 \mathrm{~g}$ of cheese were subjected to alkaline digestion in a screw-capped tube with $2 \mathrm{~mL}$ $\mathrm{KOH}(60 \%), 5 \mathrm{~mL}$ of ethanolic pyrogallic solution (6\%), $2 \mathrm{~mL}$ ethanol (96\%), and $1 \mathrm{~mL}$ $\mathrm{NaCl}(1 \%)$. All tubes were flushed with nitrogen. After saponification $\left(30 \mathrm{~min}\right.$ at $\left.70{ }^{\circ} \mathrm{C}\right)$, samples were cooled in an ice bath, added with $15 \mathrm{~mL}$ of $\mathrm{NaCl} 1 \%$, and extracted twice with $15 \mathrm{~mL}$ hexane/ethyl acetate $(9: 1 \mathrm{v} / \mathrm{v})$. The organic phase was collected and evaporated to dryness. The residue was dissolved in $2 \mathrm{~mL}$ mobile phase (2-propanol $1 \%$ in n-hexane), injected $(20 \mu \mathrm{L})$, and analyzed by normal-phase HPLC.

The chromatographic procedures were performed by a back pressure regulator system that guaranteed a 500 psi pressure increase during the chromatographic run (Upchurch Scientific, Oak Harbor, WA), a Security Guard Cartridge (Phenomenex, Torrance, CA, USA) precolumn (with silica phase), a Kromasil $5 \mu \mathrm{m} 250 \times 4.6 \mathrm{~mm}$ silica column (Phenomenex), and UV/Vis detector $(275 \mathrm{~nm})$. The mobile phase was 2propanol $1 \%$ in $\mathrm{n}$-hexane with an isocratic flow rate $\left(1.5 \mathrm{~mL} \cdot \mathrm{min}^{-1}\right)$.

\subsection{Statistical analysis}

All analyses were performed in triplicate. Data were reported as mean value with standard deviation (SD). The results of HPLC column validation procedure were subjected to ANOVA coupled with Tukey's post hoc test. Statistical treatment was performed using the KaleidaGraph 3.6 software (Synergy Software, Reading PA). 


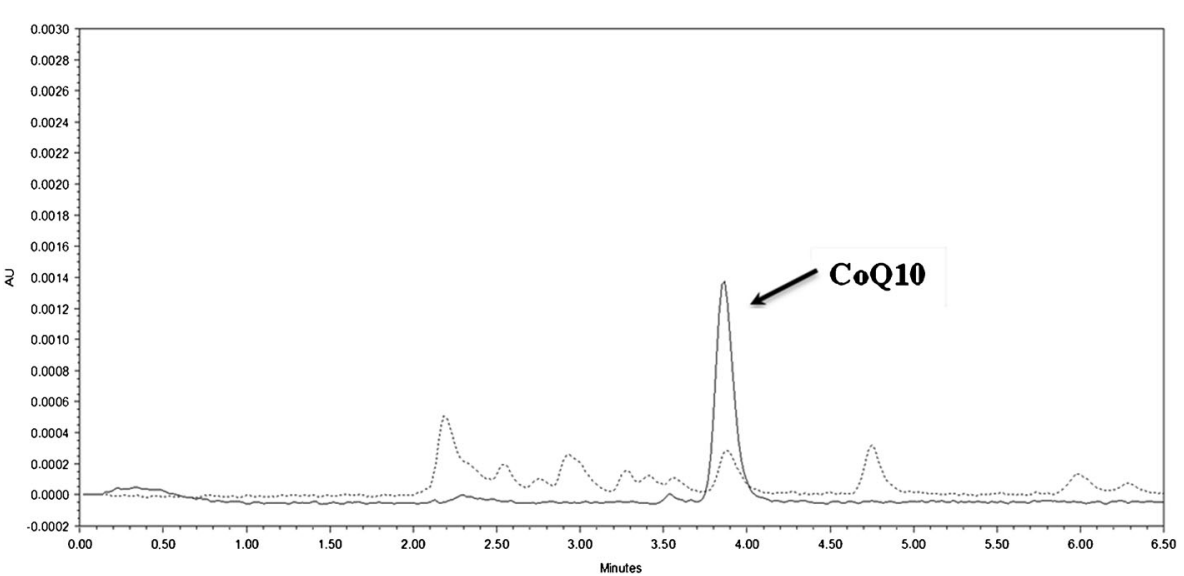

Fig. 1 HPLC chromatogram of coenzyme Q10 standard and Provola cheese (dotted line) according to chromatographic conditions reported in Section 2

\section{Results and discussion}

\subsection{Calibration, reproducibility, and recovery}

Figure 1 shows the HPLC chromatogram of CoQ10 standard and a HPLC chromatogram of Provola cheese obtained under chromatographic conditions reported in Section 2.

The linearity test for the quantification of CoQ10 was carried out over the range 0.810 $2.025 \mu \mathrm{g} \cdot \mathrm{mL}^{-1}$ and the plot of the area response $(y)$ versus concentration $(x)$ was described by the linear equation $y=13786 x-258.91$, with a good correlation $\left(R^{2}=0.9985\right)$.

According to the obtained results, the limit of detection (LOD), the lowest concentration of the analyte that can be confidently detected by this method, was $0.024 \mu \mathrm{g} . \mathrm{mL}^{-1}$; the limit of quantitation (LOQ), the lowest concentration of analyte that can be determined with an acceptable level of repeatability precision and trueness (Eurachem Guide 2014), was $0.069 \mu \mathrm{g} . \mathrm{mL}^{-1}$ with a retention time of $3.90 \mathrm{~min}$.

Repeatability and reproducibility data for the proposed method are summarized in Table 1. The intra-day procedure (repeatability) was analyzed by injecting five

Table 1 Replicate analyses of coenzyme Q10 standard

\begin{tabular}{|c|c|c|c|c|c|c|c|c|c|c|}
\hline \multirow{2}{*}{$\begin{array}{l}\text { Coenzyme Q10 } \\
\mu \mathrm{g} \cdot \mathrm{mL}^{-1}\end{array}$} & \multirow{2}{*}{$\begin{array}{l}\text { Replicates } \\
N\end{array}$} & \multicolumn{3}{|l|}{ Day 1} & \multicolumn{3}{|l|}{ Day 2} & \multicolumn{3}{|l|}{ Day 3} \\
\hline & & Peak area & $\mathrm{SD}$ & $\mathrm{RSD} \%$ & Peak area & $\mathrm{SD}$ & $\mathrm{RSD} \%$ & Peak area & $\mathrm{SD}$ & $\mathrm{RSD} \%$ \\
\hline 2.025 & 5 & 27,715 & 154 & 0.56 & 27,947 & 238 & 0.85 & 27,740 & 241 & 0.87 \\
\hline 1.620 & 5 & 21,604 & 237 & 1.10 & 21,845 & 102 & 0.47 & 21,769 & 60 & 0.28 \\
\hline 1.215 & 5 & 16,849 & 145 & 0.86 & 16,676 & 54 & 0.32 & 16,679 & 228 & 1.37 \\
\hline 0.810 & 5 & 10,993 & 119 & 1.09 & 10,679 & 221 & 2.07 & 10,901 & 43 & 0.39 \\
\hline \multicolumn{2}{|l|}{ Intra-day RSD \% } & & & 0.90 & & & 0.93 & & & 0.73 \\
\hline \multicolumn{2}{|l|}{ Inter-days RSD\% } & \multicolumn{3}{|l|}{0.85} & & & & & & \\
\hline
\end{tabular}

Peak area is reported as a mean value of five replicates with standard deviation (SD) and relative standard deviation (RSD\%) 
Table 2 Analytical recovery of coenzyme Q10 added in cheese samples

\begin{tabular}{lllr}
\hline Spiked samples & $\begin{array}{l}\mathrm{C} 1 \text { found }^{\mathrm{a}} \\
\left(\mu \mathrm{g} \cdot \mathrm{mL}^{-1}\right)\end{array}$ & $\begin{array}{l}\mathrm{C} 2 \text { theoretical } \\
\left(\mu \mathrm{g} \cdot \mathrm{mL}^{-1}\right)\end{array}$ & $\begin{array}{c}\text { Recovery } \\
(\%)\end{array}$ \\
\hline Provola cheese 1 & 1.51 & 1.53 & 98.5 \\
Provola cheese 2 & 1.54 & 1.53 & 100.9 \\
Provola cheese 3 & 2.85 & 2.93 & 97.1 \\
Provola cheese 4 & 2.90 & 2.93 & 98.9 \\
Provola cheese 5 & 0.76 & 0.78 & 98.7 \\
Provola cheese 6 & 0.77 & 0.78 & 97.8 \\
Mean & & & 98.6 \\
\hline
\end{tabular}

${ }^{\mathrm{a}} \mathrm{C} 1$ is the amount of analyte found in the sample

${ }^{\mathrm{b}} \mathrm{C} 2$ is the theoretical amount of analyte in the sample obtained by summing concentration of analyte in cheese (natural + added)

replicates per day. The relevant relative standard deviation (RSD) ranged from 0.73 to $0.93 \%$. The inter-day procedure (reproducibility) was calculated over 3 days, and $0.85 \%$ RSD value was obtained. No significant differences $(P>0.05)$ were detected in CoQ10 standard solutions in inter-day replicates.

The accuracy of the proposed method was examined, and results are shown in Table 2. A recovery test was performed by analyzing six Provola cheese samples spiked with different amounts of CoQ10 standard.

According to the obtained data, CoQ10 showed a recovery ranging from 97.1 to $100.9 \%$ that confirms the accuracy of this method.

\subsection{Method validation}

The proposed HPLC method was tested in some Italian cheeses, and relevant results are shown in Table 3. The highest value $\left(158 \mu \mathrm{g} .100 \mathrm{~g}^{-1}\right)$ of CoQ10 was obtained in Provola cheese, whereas Bagoss showed the lowest value $\left(126 \mu \mathrm{g} \cdot 100 \mathrm{~g}^{-1}\right)$.

Many studies reported the beneficial effects of CoQ10, but unfortunately, only a few of them examined the amounts of this compound in foods, especially in cheese. As regards the studies on dairy products, some authors (Mattila and Kumpullainen 2001) reported the content of CoQ10 in Emmental and Edam cheeses $\left(130-120 \mu \mathrm{g} .100 \mathrm{~g}^{-1}\right)$. Japanese researchers (Kubo et al. 2008) obtained comparable values for cheese

Table 3 Coenzyme Q10 $\left(\mu \mathrm{g} .100 \mathrm{~g}^{-1}\right)$ in Italian cheeses

\begin{tabular}{lccc}
\hline Italian cheeses & Mean & SD & RSD\% \\
\hline Provola & 158.4 & 0.2 & 0.2 \\
Pecorino (organic farm) -1 month ripening & 139.1 & 0.7 & 0.5 \\
Pecorino (conventional farm) -2 months ripening & 149.4 & 0.9 & 0.6 \\
Bagoss & 125.6 & 2.0 & 1.6 \\
\hline
\end{tabular}

Data are means of three replicate analyses with standard deviations (SD) and relative standard deviation $(\mathrm{RSD} \%)$ 
(141 $\left.\mu \mathrm{g} .100 \mathrm{~g}^{-1}\right)$ consumed in the Japanese diet. The analytical data of cheeses, obtained in this research, are therefore confirmed by data available in literature.

\section{Conclusions}

In this study, a sensitive and accurate, as well as rapid and cheap, HPLC method was developed to quantify the content of CoQ10 in cheese by normal-phase chromatography and spectrophotometric determination.

This research provides preliminary data of CoQ10 content in some Italian cheeses; however, the proposed method is promising and could be of interest in the study of dairy products such as milk, fermented milk, or PDO cheeses. Moreover, it could be of paramount importance in the investigation of the effects of technological treatments or cheese making procedures on CoQ10.

This proposed HPLC method could be useful both to quantify this bioactive compound in other foods typical of the Mediterranean diet that are rich in antioxidant compounds and to support the use of coenzyme Q10 in food fortification.

Acknowledgments This research was financially supported by the Italian Ministry "Ministero delle Politiche Agricole, Alimentari e Forestali (MiPAAF)" within the Project: QUALIFU "Qualità Alimentare e Funzionale" (D.M. 2087/7303/09). The authors thank Dr. Francesca Melini for the linguistic revision of this paper.

Conflict of interest No conflicts of interest are present.

\section{References}

Adrian AF, Morrison CM, Bakke JL, Custer LJ, Li X, Cooney RV (2010) Coenzyme Q10 in human blood: native levels and determinants of oxidation during processing and storage. Free Radic Biol Med 48:1610-1617

Ahmadvand H, Ghasemi-Dehnoo M (2014) Antiatherogenic, hepatoprotective, and hypolipidemic effects of CoQ10 inalloxan-induced type 1 diabetic rats. ARYA Atheroscler 10:192-198

Ates O, Bilen H, Keles S, Alp HH, Keles MS, Yildirim K, Öndas O, Pinar LC, Civelekler M, Baykal O (2013) Plasma CoQ10 levels in type 2 diabetic patients with retinopathy. Int J Ophthalmol 6:675-679

Bentinger M, Brismar K, Dallner G (2007) The antioxidant role of coenzyme Q. Mitochondrion 7S:S41-S50

Bentinger M, Tekle M, Dallner G (2010) Coenzyme Q- biosynthesis and functions. Biochem Biophys Res Commun 396:74-79

Crane FL (2007) Discovery of ubiquinone (coenzyme Q) and an overview of function. Mitochondrion 7:S2S7

Eurachem Guide (2014) In: Magnusson B, Örnemark U (eds) Eurachem guide: the fitness for purpose of analytical methods - a laboratory guide to method validation and related topics, 2nd edn. https://www. eurachem.org/images/stories/Guides/pdf/MV_guide_2nd_ed_EN.pdf. Accessed Feb 2015

Galinier A, Carriere A, Fernandez Y, Bessac AM, Caspar-Bauguil S, Periquet B, Comtat M, Thouvenot JP, Casteilla L (2004) Biological validation of coenzyme Q redox state by HPLC-EC measurement: relationship between coenzyme Q redox state and coenzyme Q content in rat tissues. FEBS Lett 578: 53-57

Kubo H, Fujii K, Kawabe T, Matsumoto S, Kishida H, Hoso K (2008) Food content of ubiquinol-10 and ubiquinone-10 in the Japanese diet. J Food Compos Anal 21:199-210

Mattila P, Kumpullainen J (2001) Coenzymes Q9 and Q10: contents in foods and dietary intake. J Food Compos Anal 14:409-417

Niklowitz P, Menke T, Giffei J, Andler W (2005) Coenzyme Q10 in maternal plasma and milk throughout early lactation. BioFactors 25:67-72 
Nohl H, Staniek K, Kozlov AV, Gille L (2003) The biomolecule ubiquinone exerts a variety of biological functions. BioFactors 18:23-31

Panfili G, Manzi P, Pizzoferrato L (1994) High performance liquid chromatographic method for the simultaneous determination of tocopherols, carotenes, and retinol and its geometric isomers in Italian cheeses. Analyst 119:1161-1165

Pepe S, Marasco SF, Haas SJ, Sheeran FL, Krum H, Rosenfeldt F (2007) Coenzyme Q10 in cardiovascular disease. Mitochondrion 7:S154-S167

Potgieter M, Pretorius E, Pepper MS (2013) Primary and secondary coenzyme Q10 deficiency: the role of therapeutic supplementation. Nutr Rev 71:180-188

Pravst I, Zmitek K, Zmitek J (2010) Coenzyme Q10 contents in foods and fortification strategies. Crit Rev Food Sci Nutr 50:269-280

Quinzii CM, Hirano M, Di Mauro S (2007) CoQ10 deficiency diseases in adults. Mitochondrion 7S:S122S126

Rodríguez-Acuna R, Brenne E, Lacoste F (2008) Determination of coenzyme Q10 and Q9 in vegetable oils. J Agric Food Chem 56(15):6241-6245

Rosenfeldt FL, Haas SJ, Krum H, Hadj A, Ng K, Leong JY, Watts GF (2007) Coenzyme Q10 in the treatment of hypertension: a meta-analysis of the clinical trials. J Hum Hypertens 21:297-306

Stratulat I, Britten M, Salmieri S, St-Gelais, Champagne CP, Fustier P, Lacroix M (2013) Encapsulation of coenzyme Q10 in a simple emulsion-based nutraceutical formulation and application in cheese manufacturing. Food Chem 141:2707-2712

Stratulat I, Britten M, Salmieri S, Fustier P, St-Gelais D, Champagne CP, Lacroix M (2014) Enrichment of cheese with bioactive lipophilic compounds. J Funct Foods 6:48-59

Tang PH, Miles MV, Steele P, DeGrauw A, Chuck G, Schroer L, Pesce A (2002) Anticoagulant effects on plasma coenzyme Q10 estimated by HPLC with coulometric detection. Clin Chim Acta 318:127-131

Wang Y, Hekimi S (2013) Molecular genetics of ubiquinone biosynthesis in animals. Crit Rev Biochem Mol Biol 48:69-88 